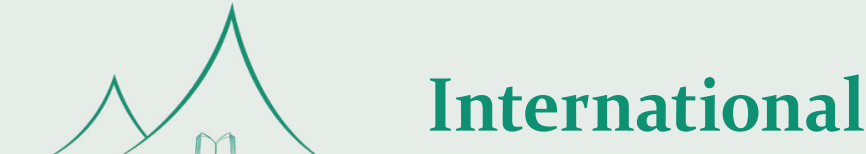 \\ madridge Journal of Material Science and Research \\ interconnecting Scientific World
}

Research Article

Open Access

\section{Fabrication and Machining of SiCN for Pressure Sensor at High Temperature for Aero-Engines Applications}

\author{
A Leo $^{1}$, SI Andronenko ${ }^{2}$ and I Stiharu ${ }^{3 *}$ \\ ${ }^{1}$ Parker Filtration Canada, Laval, Quebec, Canada \\ ${ }^{2}$ Institute of physics, Kazan Federal University, Russia \\ ${ }^{3}$ Department of Mechanical Engineering, Concordia University, Montreal, Quebec, Canada
}

\section{Article Info}

*Corresponding author:

I Stiharu

Department of Mechanical Engineering

Concordia University

Montreal, Quebec, Canada

E-mail: istih@encs.concordia.ca

Received: June 7, 2018

Accepted: June 18, 2018

Published: June 23, 2018

Citation: Leo A, Andronenko SI, Stiharu I. Fabrication and Machining of $\mathrm{SiCN}$ for Pressure Sensor at High Temperature for Aero-engines Applications. Int J Mater Sci Res. 2018; 2(1): 36-42.

doi: 10.18689/ijmsr-1000106

Copyright: ๑ 2018 The Author(s). This work is licensed under a Creative Commons Attribution 4.0 International License, which permits unrestricted use, distribution, and reproduction in any medium, provided the original work is properly cited.

Published by Madridge Publishers

\begin{abstract}
This work presents few issues related to fabrication, machining, associated to the usage of $\mathrm{SiCN}$ for pressure measurement systems that can operate under high temperature conditions. The sensor must meet the required performance without being susceptible to the influence of temperature variation. The pressure sensor as presently conceived comprises of a slender sensitive element and a thick blocking element, hence the realization of such kind of sensor requires thick film (about 2-3 mm thick) and thin film (40-60 $\mu \mathrm{m}$ thick) made of SiCN. The dimensions and thickness of the films are dependent on the application for which the sensors are intended to be used. Fabrication methods of SiCN ceramics both as thin and thick films that could be used for high temperature applications are discussed. In addition, the influences of thermosetting and annealing temperatures on mechanical properties are investigated. The material properties related to sensing properties are investigated.
\end{abstract}

Keywords: $\mathrm{SiCN}$; fabrication and machining of $\mathrm{SiCN}$; polymer derived ceramic; pressure Sensing at high temperatures; material characterization.

\section{Introduction}

Pressure measurement is required in many engineering applications as it provides valuable information for performance analysis. Such data is critical in aerospace applications where mass and accessibility represents a general constraint imposed to the designers. Measurement of pressure becomes more complicated if the zone of interest experiences high temperature. Extensive study of pressure pattern is highly desirable for condition monitoring for improved performance and accurate prediction of residual life of systems that operate under extremely high temperature such as gas turbine engine.

Several technologies have been lately investigated, but these technologies target very specific applications and they are limited by the maximum operating temperature [1-3].

$\mathrm{SiCN}$ is a polymer derived ceramic whose starting material is a liquid phase resin. This provides the advantage of molding the future part to any shape. Thick and thin films of SiCN were made to suit the proposed application. CERASET ${ }^{\mathrm{TM}}$ also yields itself for photolithography with the addition of photo initiator as 2,2-Dimethoxy-2-phenylacetophenone (DMPA) thus enabling photo lithographical patterning of the pre-ceramic polymer using UV lithography. SiCN fabrication includes thermosetting, crosslinking and pyrolysis. This technology is still under investigation to improve the stability of the process and improved performance of the material. In this respect, there are many 
engineering approaches to solve the need for new aerospace materials and technologies that constantly address issues such as viable product realisation and maintenance, performance, costs, and environmental impact concerns [4]. However, there are still many shortcomings affecting the implementation and integration of these achievements within the aerospace operations. This project aims three objectives which when accomplished, would enable development of sensors to be used in extremely harsh conditions (measurement of physical quantities at temperatures above $1000^{\circ} \mathrm{C}$. The following goals have been identified.

Goal 1: To develop new materials, based on SiCN ceramics, by incorporating appropriate transition metal ions chemically bonded to SiCN ceramic network during fabrication process with stable electric and magnetic properties up to $1900^{\circ} \mathrm{C}$. As they possess nanostructures with the size of grains from 1-2 $\mathrm{nm}$ to about $40 \mathrm{~nm}$, these materials have special properties. For example, SiCN/Fe composite exhibits superparamagnetic behaviour. Thus, they can be potentially used in spintronic devices. They also possess interesting electrical properties, e.g. they exhibit semiconducting behavior even at very high temperatures, as revealed by their conductivity measurement.

Goal 2: Exploit magnetic resonance techniques, particularly EPR (electron paramagnetic resonance) and FMR (ferromagnetic resonance), which are very sensitive methods to investigate the influence of impurity ions, dangling bonds, and defects on the physical properties of ceramic inorganic nanomaterials. The EPR parameters provide information on local environment and magnetic properties of these nanomaterials and are dependent on temperature and particle size. The SiCN ceramics developed here are granular nanomaterials with very small particle size, representing excellent models for investigation of such relationships. Despite several years of investigations, full understanding of such relations has not yet been achieved.

Goal 3: Develop reliable and low-cost technique of synthesis of these ceramic materials, and investigate the possibility to eliminate micro- and macro-porosity, as well as micro-cracking, which considerably decrease the hardness of these ceramic materials. This is accomplished through accurate control of the volatile phase evaporation in the polymer during the pyrolysis process.The long-range objective of the proposed project is to exploit the acquired knowledge to enable the fabrication of SiCN mono-crystalline semiconducting material from the polymer precursor. This paper will further report on some of the results obtained while aiming the three above stated goals.

\section{Problem Formulation}

As above mentioned, the objectives of this investigation are based on the fabrication of SiCN doped with various materials $(\mathrm{Al}, \mathrm{Fe}, \mathrm{Mn})$ that advantageously modify the properties of the ceramic such that it could be used for sensing applications. Moreover, given the mechanical properties of the ceramic resulting from the process, it is essential to evaluate the possibility to build $\mathrm{SiCN}$ in various thickness and shapes such that machining is not required while defining of the shape of the device to be built. The process of building uniform thickness plates, for an example is quite challenging as the process used for thin plates is quite different from the one used for bulk. The conversion of CEREASET ${ }^{\mathrm{TM}}$ in SiCN requires to subject the specimen to a process of cross-linking followed by a pyrolysis. The cycles of temperature and pressure are illustrated in Figure 1.

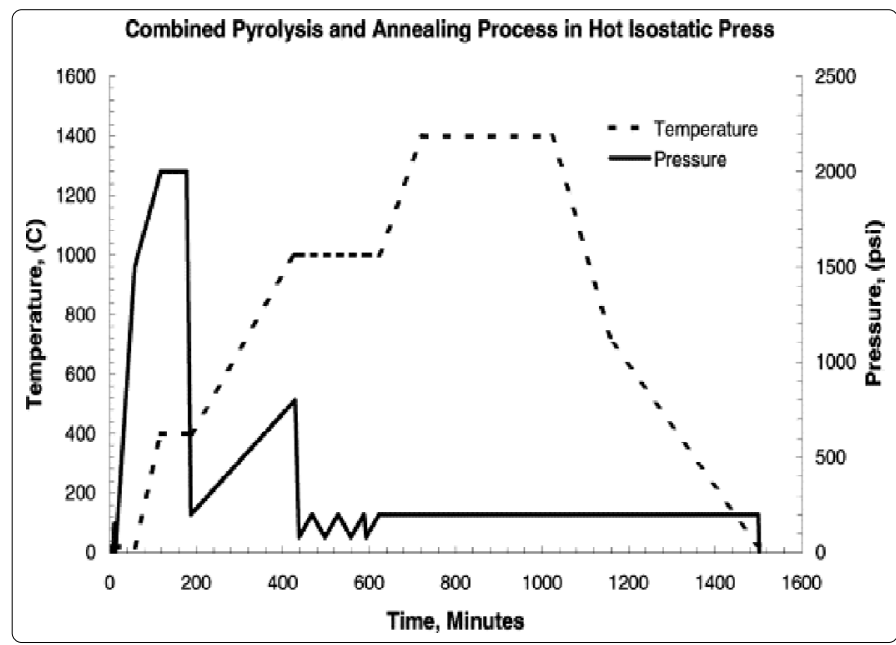

Figure 1. The pressure-temperature cycle for the pyrolysis of cross-linked CERASET into SiCN [2]

The special requirements for pressure and temperature imposed the oven used for this purpose, special features. Thus, the oven was designed to be able to yield temperatures up to $1700^{\circ} \mathrm{C}$ at a pressure of 150 atmospheres. A picture of the oven is shown in Figure 2.

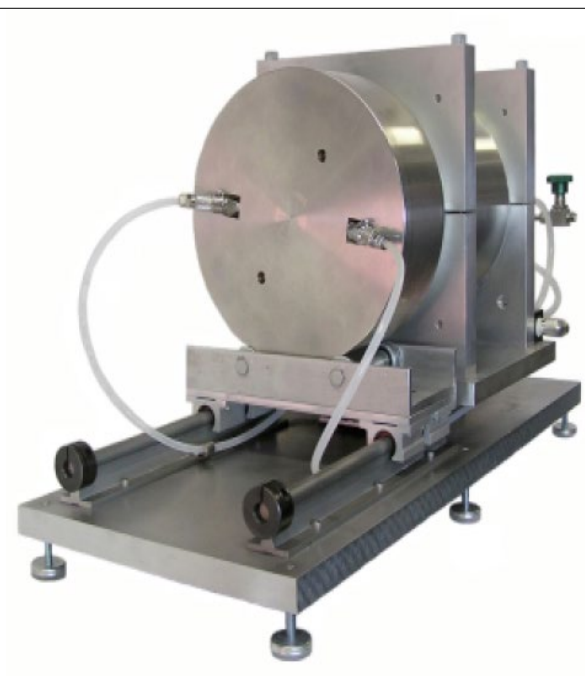

Figure 2. Custom built high pressure high temperature oven used for the pyrolysis of SiCN.

The properties on which base sensors could be built form $\mathrm{SiCN}$ are achieved by adding certain materials in the polymer. Thus, one can obtain for an example, magnetic materials with super-paramagnetic properties, which can be used as magnetic field sensors that operates under very high temperatures.

Although SiCN is an excellent material for MEMS applications, there remains many unresolved problems in the synthesis of this material. The first problem concerns the introduction of transition metal ions into $\mathrm{SiCN}$ ceramic network as a probe for EPR investigation. To date, only SiCN/ 
transition metal ions composites have been successfully fabricated wherein metal ion agglomerates were incorporated into SiCN ceramics. However, these ions are not strongly bonded to SiCN ceramic network and most of these ions are simply "wiped out" from ceramics at temperatures above $1500^{\circ} \mathrm{C}$. The second significant problem is related to the formation of micro- and macro-porosity and microcracking during polymer-derived route of developing SiCN ceramics. Micro-porosity could be partly eliminated by application of isostatic pressure during crosslinking. In general, porosity formation mechanism has not been well investigated. Microcracks are potentially related to incomplete chemical reaction and bonding at pyrolysis temperature ranging from $1100^{\circ} \mathrm{C}$ to $1400^{\circ} \mathrm{C}$. The structure of ceramics is weak in this temperature range. As an additional problem, single crystals of SiCN have not yet been grown. Single crystal development enables great opportunities in the application of this material in MEMS sensors. The review of recent achievements in the synthesis of polymer-derived SiCN ceramics was provided in [5].

The piezoelectric properties of this material have also been investigated for practical use $[6,7]$. Realization of monocrystalline SiCN material would represent an outstanding achievement. The pressure sensor, based on piezoelectric properties, could be created in this case. Another property of SiCN ceramics, which can be exploited for practical use, is its excellent microwave absorption performance $[8,9,10]$.

It is possible also tailoring electric properties of SiCN ceramics, from dielectrics to semiconductor [11, 12]. These properties can be modified with doping of boron or aluminium to initial polymer precursor. It provides a possibility to create high-temperature electronic devices. The SiCN ceramics can be used also as thermistor, temperature-sensitive resistor, in control devices [13]. It is foreseen that the results of investigation such as the one presented here will ultimately lead to that goal.

\section{Mechanical Properties}

The use of SiCN from polymer precursor is driven by few factors, which include:

- Functional temperature - up to $1900^{\circ} \mathrm{C}$.

- Low thermal expansion coefficient. TEC $\times 10-6=0.5$ - similar to $\mathrm{SiO} 2$

- Hardness: about $25 \mathrm{GPa}$

- Very high creep resistance.

- Very high fracture strength: 500 -1200 MPa

- High oxidation resistance.

- High thermal shock resistance (FoM): 1100-5000

- CERASET $^{\text {тм }}$ polysilazane precursor is commercially available from KION Inc.

- CERASET $^{\mathrm{TM}}$ polymer precursor is in liquid state and therefore can be shaped easily.

Thus, the fabrication process was followed by numerous tests carried out to evaluate the overall performances of the material. The following findings are presented below

\section{The IR spectrum of the pyrolised SiCN as a function of the} pyrolysis temperature

The IR spectra were recorded on Specord M80 Carl Zeiss. IR spectra of SiCN compounds only display the elimination of the band near $3400 \mathrm{~cm}-1$ at higher temperature. This band (3383 cm-1) corresponds to $\mathrm{N}-\mathrm{H}$ bond. The weak band at $2129 \mathrm{~cm}-1$ corresponds to $\mathrm{Si}-\mathrm{H}$ bond. This figure shows full disappearance of $\mathrm{H}$ atoms from SiCN ceramics at pyrolysis temperature $1150-1200^{\circ} \mathrm{C}$. The band at $2400 \mathrm{~cm}-1$ corresponds to $\mathrm{CO} 2$ gas from atmosphere. Weak band at $1600^{\circ} \mathrm{cm}-1$ corresponds to $\mathrm{C}=\mathrm{O}$ bonds. Large band in the range $900-1100 \mathrm{~cm}-1$ corresponds to $\mathrm{Si}-\mathrm{N}$ and $\mathrm{Si}-\mathrm{C}$ bonds (Si, $\mathrm{N}$ and $\mathrm{C}$ ions are main components of this compound).

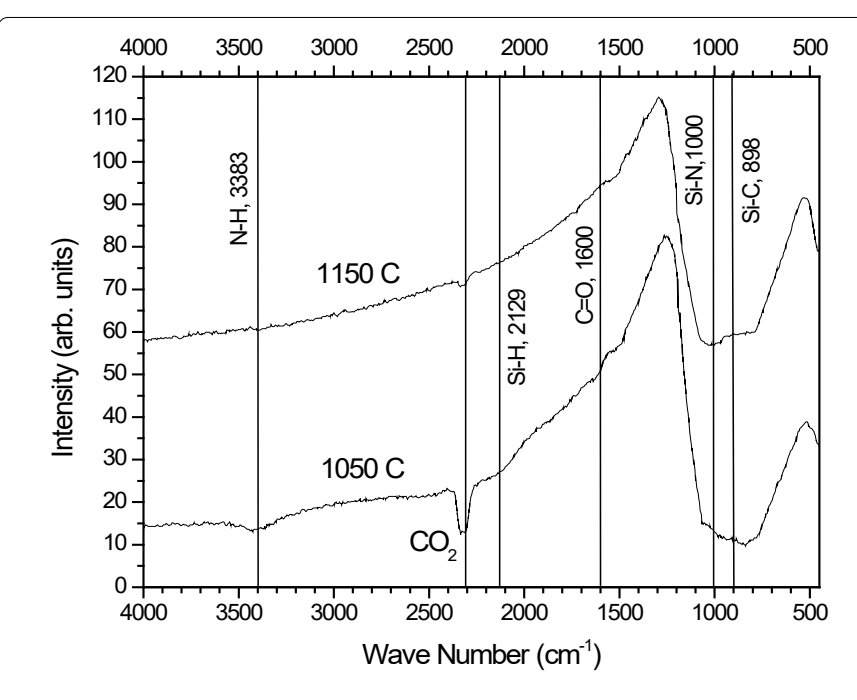

Figure 3. The IR-spectra for pyrolysed SiCN ceramics for different pyrolysis temperatures

\section{The hardness of the material}

The hardness test for the material was performed with a microindenter on a Vikers machine. The analysis of the microindentation revealed that the hardness of SiCN obtained from polymer precursor by crosslinking and pyrolysis is in average of $25 \mathrm{Gpa}$. The specimen crosslinked with higher isostatic pressure $\sim 2000$ psi and pylolyzed and annealed at a higher tempertaure in the range of $1200^{\circ} \mathrm{C}$ had a recorded peak of 28 Gpa Figure 4 illustrates for comparison, the microindentation in SiCN and on 316 stainless steel.

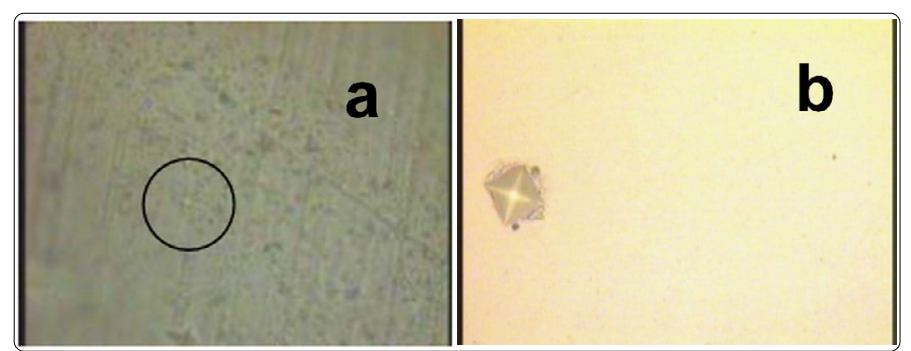

Figure 4. Micro-indentation test on (Fig. 4a) $\mathrm{SiCN}(\mathrm{HV}=28 \mathrm{GPa})$ and (Fig. 4b) 316 stainess steel (HV=4.5 GPa) The X-Ray diffractogram of the SiCN from polymer precursor
(CERASETTM) pyrolysed at $1000^{\circ} \mathrm{C}, 1100^{\circ} \mathrm{C}$ and $1200^{\circ} \mathrm{C}$.

These X-ray patterns are characterized by the peaks at low angles (at $15^{\circ}$ ). There is a special method to investigate 
amorphous, glass-like compounds, known as small angle $\mathrm{X}$-ray diffraction) and the lack of narrow sharp peaks are characteristic for amorphous state. Figure 5 features the results. The peak at $31^{\circ}$ (for $1000^{\circ} \mathrm{C}$ pyrolysis pattern) is not identifiable and probably is related to carbon crystallite.

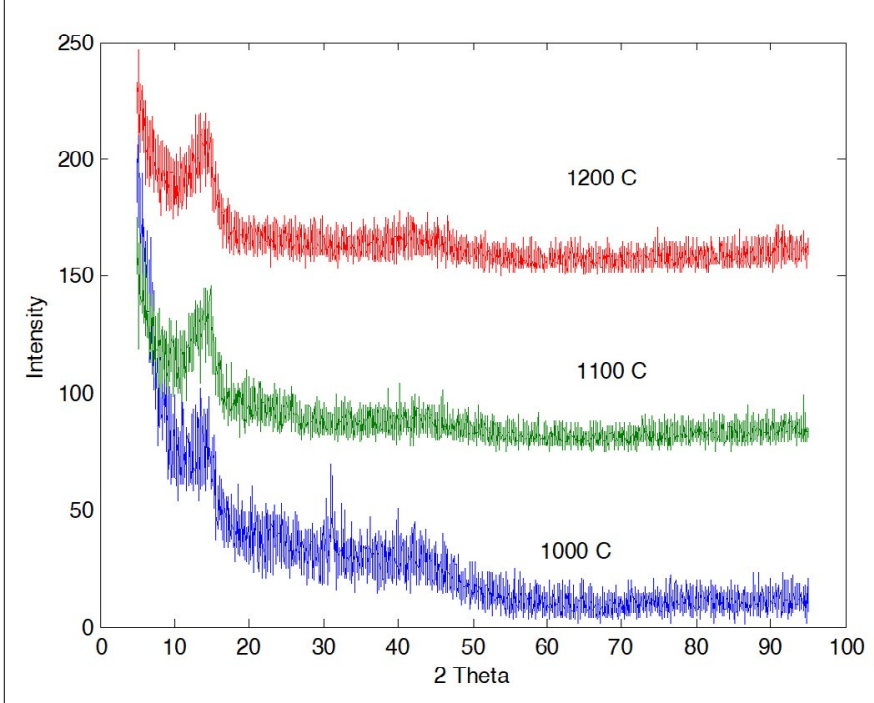

Figure 5. X-ray diffractogram for CERASET-derived SiCN specimen, pyrolyzed at different temperatures

\section{Electron Paramagnetic Resonance Spectroscopy}

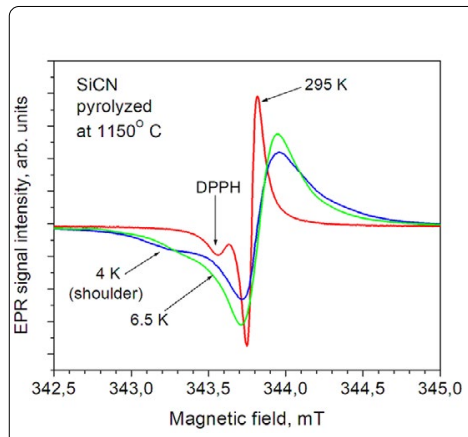

a)

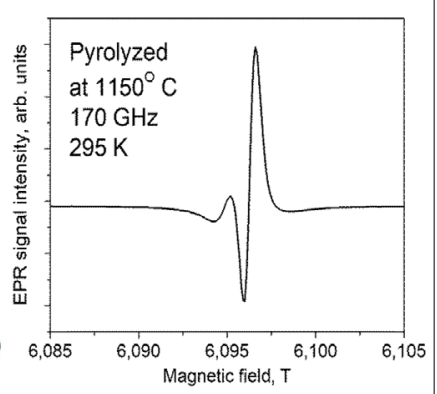

b)
Figure 6. EPR spectra of carbon $\mathrm{sp}^{2}$ dangling bonds at different temperatures in SiCN ceramics,

a) $9.6 \mathrm{GHz}$, SiCN pyrolysed at $1150^{\circ} \mathrm{C}$,

b) $170 \mathrm{GHz}$, SiCN pyrolysed at $1150^{\circ} \mathrm{C}$ [2]

Figure 6 illustrates the results of the experimental investigations. The EPR investigation for defects was carried out at room temperature and at liquid helium temperature ranges. Strong temperature dependence was found for $\mathrm{g}$-value and linewidth. At high temperature they correspond to usual carbon dangling bonds value; $g=2.0027$, the linewidth depends on temperature treatment and it changes from 0.7 to $3 \mathrm{G}$. At lowest temperature the linewidth increases and g-value decreases, and temperature dependence of EPR linewidth in helium temperature range is described by the expression given by Misra [2] and fully explained by exchange interactions in the clusters of carbon dangling bonds. The exchange constant $J$ can be estimated from temperature dependence of EPR linewidth, J = 10-15 K. There is a difference between two kind of specimens: pyrolysed below $1000^{\circ} \mathrm{C}$ and annealed above $1100^{\circ} \mathrm{C}$. The latter has lower EPR linewidth and no significant temperature dependence of EPR linewidth and $g$-value. Lowest EPR spectrum (in annealing sample) seems to show complex shape for EPR line. EPR line is the superposition of two EPR lines with different linewidth. This was proved with use of high-frequency EPR study of this material as it is show in Fig. 6b. Main part is due to free carbon and other part is probably due to dangling bonds in bulk $\mathrm{SiCN}$ network. This EPR line characterizes dangling bonds, e.g. incompleteness of chemical structure of SiCN ceramics and, consequently, hardness of ceramics.

The investigation of its integral intensity on annealing temperature shows that the intensity of EPR line has a maximum at $1100^{\circ} \mathrm{C}$ and decreases with annealing temperature increasing. These dangling bonds can be assigned to so-called "free carbon" phase, which formed at about $800^{\circ} \mathrm{C}$ along with carbon ions bonded to $\mathrm{Si}$ and $\mathrm{N}$ ions. The carbon ions in this phase are aromatically bonded into "graphene"-like structure and dangling bonds are defects of this structure. Therefore, study of the EPR intensity gives a possibility to find the synthesis conditions of SiCN ceramics with decreasing number of dangling bonds, so as to improve structure quality. The optimal annealing temperature turned out to be $1400^{\circ} \mathrm{C}$.

\section{Magnetic properties of SiCN ceramics, doped with transition metal ions}

One problem identified here is to make magnetic material, where transition metal ions were chemically bonded to $\mathrm{SiCN}$ ceramic network, rather not included in this material as metal particles.

Superparamagnetic behiviour occurs when the material includes of very small crystallites (1-10 nm) of transitionmetal ions such as $\mathrm{Fe}, \mathrm{Mn}, \mathrm{Ni}$, Co of homogeneous fashion. When the temperature is low the thermal energy is not sufficient to break the coupling between adjacent atomic paramagnets within a crystallite. Thus, the magnetic moment of the entire crystallite, rather that of an individual atom, interacts with the magnetic field. SiCN ceramics consist of nanoparticles with an average size of 1.3 to $40 \mathrm{~nm}$, depending on annealing temperature. The magnetic impurities, e.g. Fe, $\mathrm{Mn}, \mathrm{Ni}$, Co form nanoparticles inside SiCN ceramics with approximately the same dimensions. Super paramagnetism then arises from the coupling of the magnetic moments of the individual transition metal ions within these nanoparticles and it can be detected and investigated by EPR spectroscopy. The temperature dependence of EPR linewidth, $g$-value and lineshape reflect with very high sensitivity the changes in the magnetic behavior of these metal nanoparticles. The so called "soft" magnets based on SiCN nanostructured ceramic samples with very low coercivity and negligible magnetic hysteresis are defined to be the ones in which very large changes in the magnetic flux density can be produced by very small magnetic fields. Therefore, very sensitive magnetic sensors can be fabricated from SiCN ceramics. This kind of hysteresis, typical for SiCN/Fe ceramics, was shown in Fig. 7. 


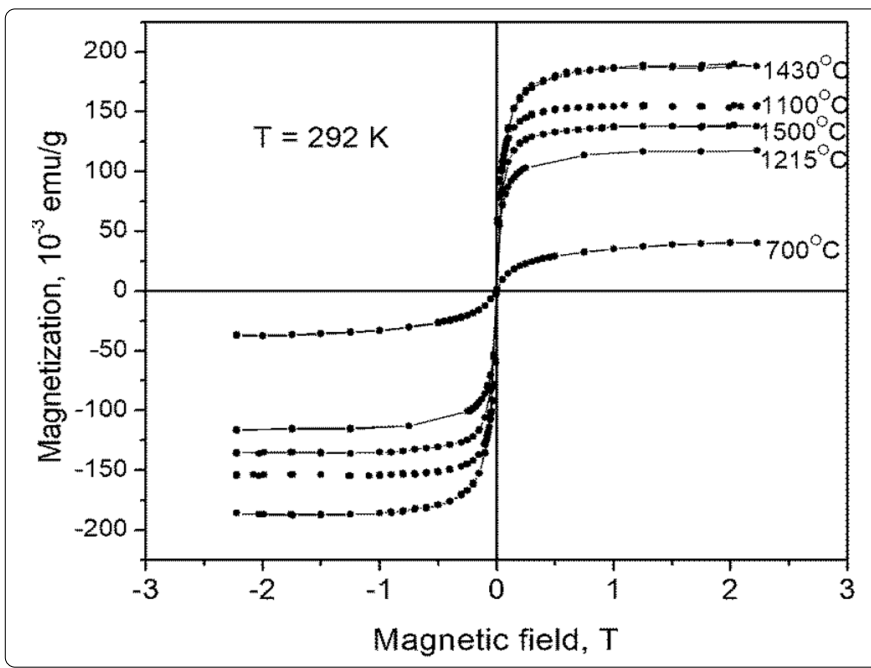

Figure 7. The magnetic-field dependencies of the magnetizations at $292 \mathrm{~K}$, for the various $\mathrm{SiCN} / \mathrm{Fe}$ nanoceramics annealed at $700^{\circ} \mathrm{C}$, $1100^{\circ} \mathrm{C}, 1215^{\circ} \mathrm{C}, 1430^{\circ} \mathrm{C},(\mathrm{e}) 1500^{\circ} \mathrm{C}$ [14].

The use of high temperature furnace enables to investigate several phase transitions and transformations in the system $\mathrm{SiCN} / \mathrm{Fe}$ ceramics, pyrolyzed at the temperatures from $600^{\circ} \mathrm{C}$ to $1600^{\circ} \mathrm{C}$. Several spectroscopic techniques, like FTIR, Raman spectroscopy, EPR spectroscopy, as well as X-ray powder diffractometry, were used to investigate SiCN/Fe ceramic samples and separate different sources of magnetization in these materials. As it was found, main source of magnetization is $\mathrm{Fe}_{5} \mathrm{Si}_{3}$ nanoparticles, along with $\alpha$-Fe nanoparticles [14]. Finally, it was found, that most homogeneous magnetic material can be obtained at annealing temperature above $1400^{\circ} \mathrm{C}$. The SiCN/Mn magnetic ceramics exhibits similar soft-magnetic properties [15]. The main source of magnetism in this material is $\mathrm{Mn}_{5} \mathrm{Si}_{3}$ nanoparticles, dispersed over diamagnetic SiCN ceramics.

\section{Machining of SiCN}

Machining using conventional means is not a choice for this type of material. However, non-traditional machining such a laser machining represents one of the options to produce through-features in SiCN. Figure 8 illustrates a square hole through a $800 \mu \mathrm{m}$ thick SiCN for two different feed rates. A femtosecond laser with a power of $50 \mathrm{~mW}$ top and left side were machined at $50 \mathrm{~mm} / \mathrm{sec}$. The spot was fixed at $10 \mu \mathrm{m}$ diameter. The bottom and right side of the square were machined at $15 \mu \mathrm{m} / \mathrm{sec}$ while the top and left side were machined at $50 \mu \mathrm{m} / \mathrm{sec}$. Figure 8.Any form of opening can be produced by direct femtosecond laser micromachining. The holes size depends strongly on the ceramics properties while the quality of the edge depends on the feed rate.

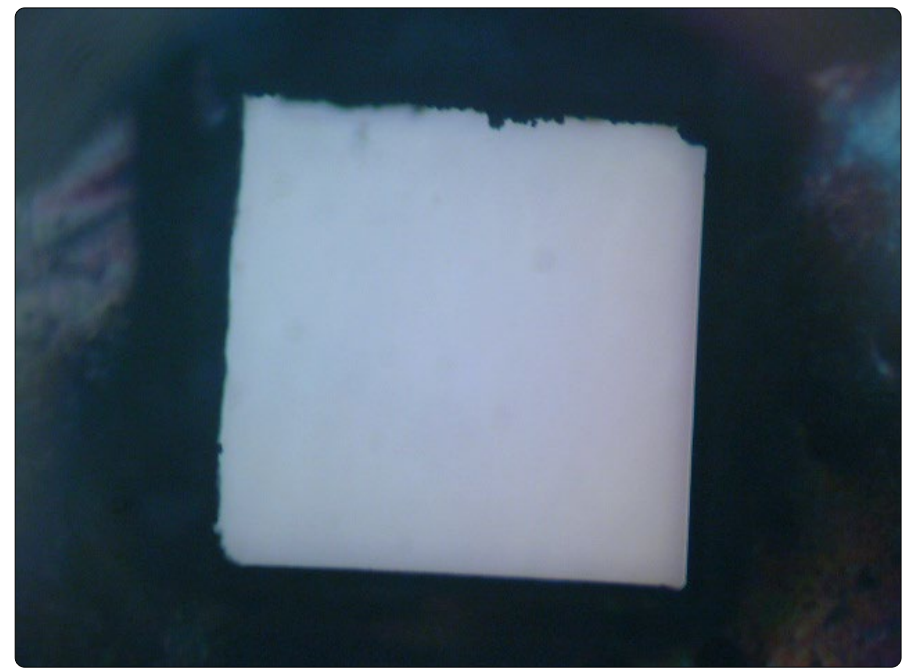

Figure 8. Machining of SiCN. A square hole was performed through thick $(800 \boldsymbol{\mu m}) \mathrm{SiCN}$ using laser ablation. The slow rate yields the smooth edges (right and low) while the high rate produces the uneven edges (top and left)

The roughness of the machined surface was evaluated by optical profilometry. The results of one of the measurements is illustrated in Figure 9. The results of the optical analysis using the optical profilometer show very good quality of the surface of the cut line for low feed rate of the femtosecond laser. Although the reflectivity is somehow reduced due to the high absorbance of the surface, the measurements show that the roughness in both directions would not exceed few tens of nm. Unfortunately, no systematic investigation was carried out along this side of the research.

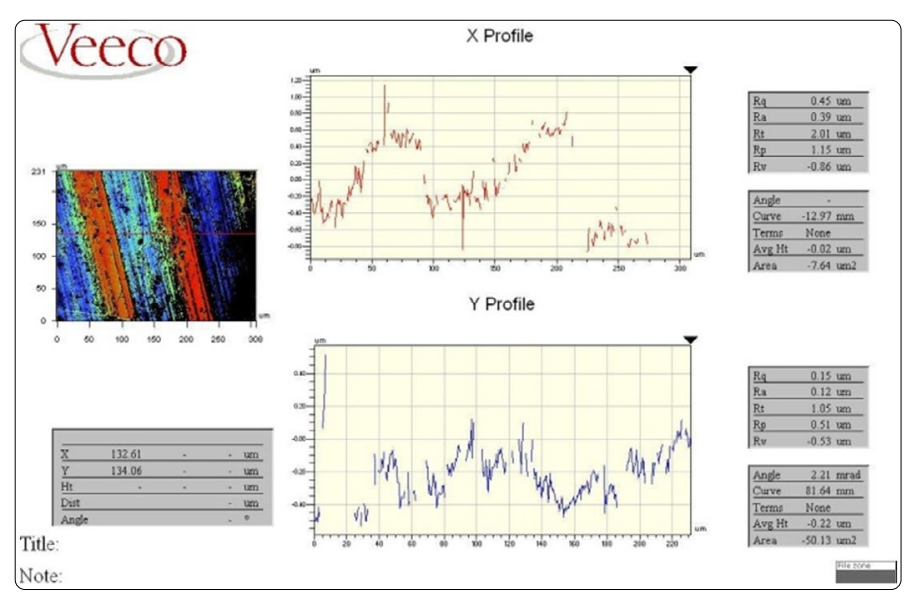

Figure 9. Optical profilometer results. The roughness of the scanned surface was of $\mathrm{Ra}=0.12 \mu \mathrm{m}$

Figure 10. Shows a circle made by laser ablation performed on the SiCN ceramic. The absorbed laser energy is converted to thermal energy which is transferred into the lattice in a picosecond time scale. Thermal diffusion into the material is minimal and ablation occurs in vapor phase, absence of insignificant amount of liquid phase provides better control of the machining. Due to the fragile nature of the ceramic the thickness of the ablated line is a much larger (10-100 $\mu$ ) compared to an optimal thickness of $5 \mu$. 


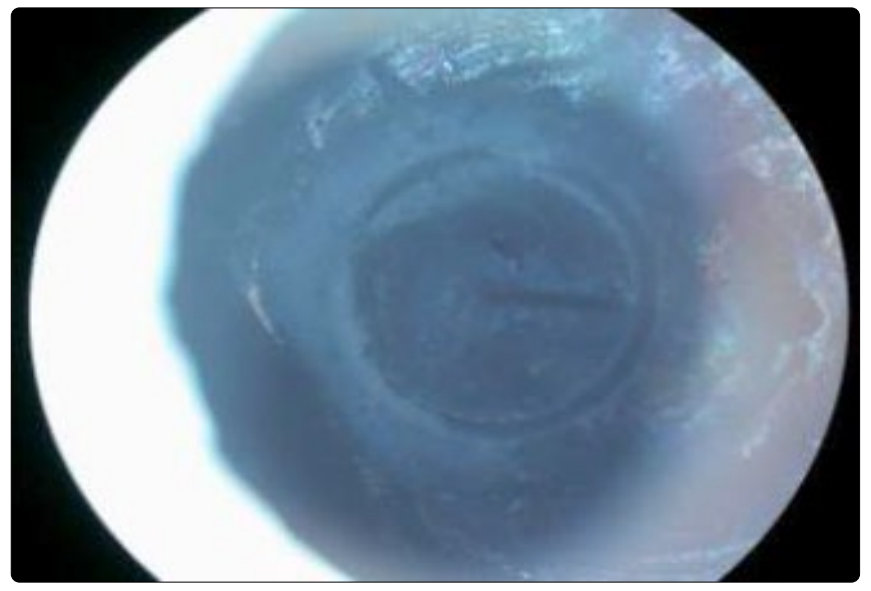

Figure 10. Laser ablation on SiCN. Thin SiCN ( $5 \mu \mathrm{m}$ thick) was shaped by laser ablation.

\section{The Unsolved Problems}

The experience acquired by performing this work gave confidence that such type of materials may represent a future solution for the applications in which more controls and thus sensors need to be involved. However, the fabrication method as conceived so far which is mainly based on the existent literature and on the acquired experience lead to many unanswered questions. For an example, despite the precautions taken with every single batch (the process takes a bit more than a full day) would not exclude possibility of producing materials with relatively different properties. The variance is most likely due to the cross-linking process and thus on the small variance of the cross-linking conditions. However, such hypothesis needs to be validated.

The thin films of SiCN were synthesized on a sacrificial film. The spin-coated such deposited CERASET ${ }^{\mathrm{TM}}$ is further cross-linked while attached on the sacrificial film. After the cross-linking the films are still planar but after pyrolysis, they curl and a proper method to achieve planar film needs to be investigated. The literature mention usage of a graphite block set on the top of the film but such approach is far from a batch fabrication technique. Figure 11 illustrates such an example of curled film of SiCN after the pyrolysis process.

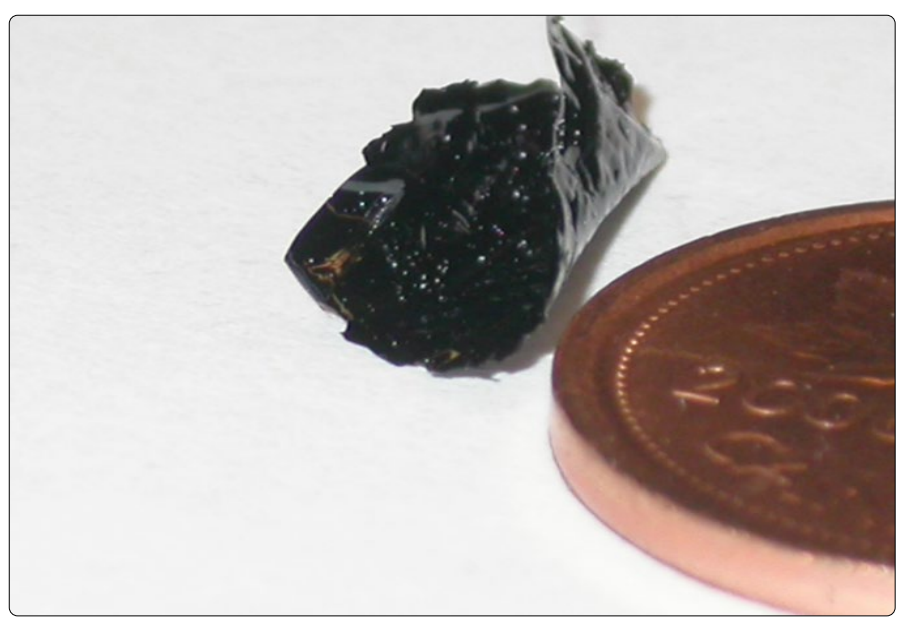

Figure 11. Curling of thin film SiCN. Thin films of SiCN may curl after cooling as thermal stress is expected to be encountered. Any variation in structure yields to non-homogenity throughout the thickness of the structure. When the temperature drops, the differential shrinkage rate yields curling of thin (5 $\mu \mathrm{m}$ thick) SiCN
Figure 10 shows the shape of thin film SiCN. The plate is curled up because of the compression encountered on the top layer, the top surface encounters large non-uniformities. Thin films in the range of 32 microns were fabricated using graphite blocks but is still there is a need for mass production technique. [16].

Finally, an extensive area of research is defined by the possibility to create new materials with extreme properties that could be used for demanding applications which is still out of reach of commercially available materials. Such application include measurement in the high-pressure compressor, flame stability in the burner or performance of the gas turbine in the turbo-aircraft engines. Long term stability of thin film sensors made of noble metal has been demonstrated to work at $1100^{\circ} \mathrm{C}$ for only 25 hours and SiCN based sensor could be a solution to enhance the life of sensors in extreme situations [17].

It is obvious that the laboratory level investigations need to be taken up by companies that develop sensors. However, such companies may have less interest in developing such new materials as their work is on sensor development. Given the inter-disciplinary aspect of this research, there is a good chance that such a topic will stay within the academic level for quite some time.

\section{Conclusion}

This work shows, that SiCN ceramics derived from commercially available liquid polymer precursor CERASET ${ }^{\mathrm{TM}}$, can be successfully used to create different shaped ceramics details. The mechanical, electrical and magnetic properties of SiCN ceramics can be modified with addition different chemicals in liquid polymer. Magnetic materials, like SiCN/Fe is of special interest, because they can be used in high temperature MEMS applications as very sensitive magnetic field sensors.This work clearly shows, that at first step, by using a tube furnace with maximum temperature $1200^{\circ} \mathrm{C}$, one could not reach SiCN ceramics with good mechanical properties. SiCN ceramics synthesized these temperatures and atmospheric pressure are very weak, with increased number of dangling bonds. Chemical transformation completed at about $1400^{\circ} \mathrm{C}$ in a high temperature high pressure furnace could provide appropriate condition for synthesis of this material.As it is well known, it is quite demanding to fabricate material with high hardness and low brittleness. The plasticity of such material is very low also and it is necessary to increase the plasticity.Many helpful applications of liquid polymer precursor technique were developed during the tenure of this project such as very thin film fabrication, ceramic coating on different surfaces, or SiCN patterning on the different substrates. Many efforts were made to develop modified SiCN ceramics with enhanced electrical or magnetic properties.Long term stability of thin film sensors made of noble metal has been demonstrated to work at $1100 \mathrm{C}$ for only 25 hours and SiCN based sensor could be a solution to enhance the life of sensors in such extreme situations [17]. 


\section{References}

1. Anne Li, Liew, Zhang W, Bright VM, An L, Dunn ML, et al. Fabrication of SiCN ceramics MEMS using injectable polymer-precursor technique. Sensors and Actuators. 2001; 64-70. doi: 10.1016/S0924-4247(00)00545-8

2. Andronenko SI, Stiharu I, Misra SK. Synthesis and characterization of polyureasilazane derived SiCN ceramics. Journal of Applied Physics. 2006; 99: 113907. doi: 10.1063/1.2202291

3. Bright VM, Raj R, Dunn ML, Daily JW. Injectable Ceramic Microcast Silicon Carbonitride (SiCN) microelectromechanical System (MEMS) for Extreme Temperature Environments with Extension. Micro Packages for NanoDevices (Colorado University), AFRL-IF-RS-TR-2004, Final Technical Report.

4. Anne Li, Liew, Saravanan RA, Bright VM, Dunn ML, Daily JW, et al. Processing and characterization of silicon carbon-nitride ceramics: application of electrical properties toward MEMS thermal actuators. Sensors and Actuators A. 2003; 171-181. doi: 10.1016/\$0924-4247(02)00330-8

5. Mera G, Gallei M, Bernard S, lonescu E. Ceramic nanocomposites from tailor-made preceramics polymers. Nanomaterials. 2015; 2: 468-540. doi: 10.3390/nano5020468

6. Zhang L, Wang $Y$, Wei $Y, X u$ W, Fang $D$, et al. Silicon carbonitride ceramic with anomalously high piezoresistivity. J. Am. Ceram. Soc. 2008; 91: 13461349. doi: 10.1111/j.1551-2916.2008.02275.x

7. Wang $Y$, Zhang $L$, Fan $Y$, Jiang $D$. Stress dependent piezoresistivity of tunneling percolation systems. J Mater. Sci. 2009; 44: 2814-2819. doi: 10.1007/s10853-009-3371-5

8. Feng $Y$, Guo $X$, Gong $H$, Zhang $Y$, Liu Y. Microwave absorption performance of PDCs-SiCN(Fe) ceramics with negative imaginary permeability. Ceramics International. 2018; 44 (9): 10420-10425. doi: 10.1016/j.ceramint.2018.03.058

9. Wang $Y$, Guo $X$, Feng $Y$, Lin $X$, Gong $H$. Wave absorbing performance of polymer-derived SiCN(Fe) ceramics. Ceramics International. 2017; 43(17): 15551-15555. doi: 10.1016/j.ceramint.2017.08.106
10. Guo $X$, Feng $Y$, Lin $X$, Liu $Y$, Gong $H$, et al. The dielectric and microwave absorption properties of polymer-derived SiCN ceramics. J. Eur. Ceram. Soc. 2018; 38(4): 1327-1333. doi: 10.1016/j.jeurceramsoc.2017.10.031

11. Hermann AM, Wang YT, Ramakrishnan PA, Balzar DL. Haluschka. Structure and electronic properties of Si-(B)- C-N ceramics. J. Am. Ceram. Soc. 2001; 84: 2260-2264. doi: 10.1111/j.1151-2916.2001.tb00999.x

12. Ramakrishnan PA, Wang YT, Balzar D, Riedel R, Hermann AM, et al. Silicoboroncarbonitride ceramics: A class of high temperature dopable electronic materials. Appl. Phys. Lett. 2001; 78: 3076-3078. doi: 10.1063/1.1370540

13. Ma B, Cao Y, Gao Y, Wang Y. Fabrication of a thin double-layer termistor based on DVB-modified polymer-derived SiCN ceramics. J. Alloys Compd. 2018; 732: 491-497. doi: 10.1016/j.jallcom.2017.10.242

14. Leo A, Andronenko S, Stiharu I, Misra S. EPR/FMR investigation on Mndoped SiCN ceramics. Applied Magnetic Resonance. 2010; 39(4): 347-356. doi: 10.1007/s00723-010-0163-7

15. Andronenko S, Stiharu I, Misra S. EPR, FMR, FTIR, X-ray and Raman investigation on Fe-doped SiCN. Appied Magnetic Resonance. 2010; 38 : 385-402. doi: 10.1007/s00723-010-0120-5

16. Leo A, Andronenko S, Stiharu I, Bhat RB. Characterization of thick and thin film SiCN for pressure sensing at High Temperature. Sensors. 2010; 10: 1338-1354. doi: $10.3390 / s 100201338$

17. Nagaiah NR, Kapat JS, Ana L, Chow DL. Novel polymer derived ceramic - High temperature heat flux sensor for gas turbine Environment. Journal of physics:Conference series. 2006; 34:458-463. doi: 10.1088/1742-6596/34/1/075 